\title{
Problems and Countermeasures of Medical-Nursing Integrated Services in Chongqing's Private Pension Agencies: A Qualitative Study
}

\author{
Xue Du' ${ }^{1,2,3} 3^{*}$, Wenxia Li1,2,3*, Qian Peng1,2,3, Lijun Wang1,2,3 Jun Ma1,2,3\# \\ ${ }^{1}$ School of Public Health and Management, Chongqing Medical University, Chongqing, China \\ ${ }^{2}$ Research Center for Medicine and Social Development, Chongqing Medical University, Chongqing, China \\ ${ }^{3}$ Collaborative Innovation Center of Social Risks Governance in Health, Chongqing Medical University, Chongqing, China \\ Email: "fairlily1117@163.com
}

How to cite this paper: Du, X., Li, W.X., Peng, Q., Wang, L.J. and Ma, J. (2021) Problems and Countermeasures of MedicalNursing Integrated Services in Chongqing's Private Pension Agencies: A Qualitative Study. Open Access Library Journal, 8: e7127. https://doi.org/10.4236/oalib.1107127

Received: December 29, 2020

Accepted: January 25, 2021

Published: January 28, 2021

Copyright $\odot 2021$ by author(s) and Open Access Library Inc.

This work is licensed under the Creative Commons Attribution International License (CC BY 4.0).

http://creativecommons.org/licenses/by/4.0/

\begin{abstract}
Background: The integration of medical and nursing has been gradually carried out in recent years, but the weak family pension and insufficient community pension at this stage are not enough to support the integration of medical and nursing in China. Therefore, it is of great significance to improve medical-nursing integrated services in pension agencies by investigating their current status. Objective: To explore the main problems of medical-nursing integrated services in private pension agencies through understanding their current situation, and provide countermeasures for optimizing the medical-nursing integrated services. Methods: We selected 6 pension agencies for investigation according to the combination mode of medical and nursing with stratified sampling method, then interviewed 6 managers from 6 private pension agencies with in-depth interview from December 2019 to January 2020, finally analyzed and summarized the interview data with the Colaizzi 7-step analysis method. Results: The main problems of medical-nursing integrated services in private pension agencies are lack of medical service standards, poor integration of medical and nursing, insufficient number and low quality of medical-nursing integrated service team, lack of policy support, single fund-raising channel for pension agencies and heavy financial burden of high service fee for the elderly. Conclusion: The countermeasures to solve the above problems are clarifying the goals of medical services, strengthening the construction of medical-nursing integrated service team, increasing policy support and investment, and accelerating the popularization of the long-term care insurance system.
\end{abstract}




\section{Subject Areas}

Health Policy, Nursing

\section{Keywords}

Integration of Medical and Nursing, Pension Agency, Service Status, Qualitative Research

\section{Introduction}

China had 254 million people aged 60 or above by the end of 2019, accounting for $18.1 \%$ of the total [1]. Among them, about 50 million aging people are disabled or semi-disabled, accounting for $20 \%$ of the total aging population [2]. Therefore, aging of population was a serious challenge facing China, especially the large number of disabled and semi-disabled aging people brought heavy pressure to families, communities and society. In this context, pension agency integrated medical and nursing has become an important approach to solve the problem of population aging and the care for aging people with disabilities [3]. However, domestic studies on the integration of medical and nursing in the past two years mainly focused on the models and policies [4] [5] [6] [7], and there are few studies on the current status of integrating medical and nursing in pension agencies. Chongqing is a national pilot area for the integration of medical and nursing. According to 13th Five Year Plan for the Development of Chongqing's Aging Career and the Elderly Care System, the Chongqing Municipal Government has listed the pension agency integrated medical and nursing and social forces as an important way to solve the current pension problems [8]. This study conducted qualitative interviews with the managers of Chongqing's private pension agencies in order to understand the problems in private pension agencies' integration of medical and nursing, and provide countermeasures and suggestions for optimizing relevant services.

\section{Objectives and Methods}

\subsection{Research Objectives}

Considering District A of Chongqing as a national pilot area for integration of medical and nursing and its rich experience in integration of medical and nursing, this study selected District A of Chongqing as the research jurisdiction. From December 2019 to January 2020, we selected 6 managers from 6 private pension agencies in District $A$ as interviewees in accordance with the combination mode of medical and nursing (internal hospital, internal clinic, and cooperation with hospitals nearby) by the stratified sampling method. The interviewees were coded from A to $\mathrm{E}$. The basic information of 6 pension agencies is shown in Table 1. 
Table 1. Basic information of 6 pension agencies.

\begin{tabular}{|c|c|c|c|c|c|c|}
\hline No & $\begin{array}{l}\text { Established } \\
\text { time }\end{array}$ & $\begin{array}{l}\text { Occupied } \\
\text { area }\end{array}$ & BedNum & $\begin{array}{l}\text { Number of elderly } \\
\text { (occupancy rate) }\end{array}$ & $\begin{array}{l}\text { Combination } \\
\text { mode }\end{array}$ & $\begin{array}{c}\text { Charge interval } \\
(¥)\end{array}$ \\
\hline A & 2012 & $60,000 \mathrm{~m}^{2}$ & 850 & $\begin{array}{c}660 \\
(77.65 \%)\end{array}$ & internal hospital & $3500-10,000$ \\
\hline B & 2014 & $100,000 \mathrm{~m}^{2}$ & 520 & $\begin{array}{c}406 \\
(78.08 \%)\end{array}$ & internal hospital & $3000-5300$ \\
\hline $\mathrm{C}$ & 2008 & $5000 \mathrm{~m}^{2}$ & 180 & $\begin{array}{c}130 \\
(72.22 \%)\end{array}$ & internal clinic & $1600-5000$ \\
\hline $\mathrm{D}$ & 2002 & $10,000 \mathrm{~m}^{2}$ & 300 & $\begin{array}{c}140 \\
(46.67 \%)\end{array}$ & internal clinic & $1600-4000$ \\
\hline $\mathrm{E}$ & 2003 & $4000 \mathrm{~m}^{2}$ & 120 & $\begin{array}{c}64 \\
(53.33 \%)\end{array}$ & $\begin{array}{l}\text { cooperation with } \\
\text { hospitals nearby }\end{array}$ & $1500-5500$ \\
\hline $\mathrm{F}$ & 2008 & $1000 \mathrm{~m}^{2}$ & 50 & $\begin{array}{c}38 \\
(76 \%)\end{array}$ & $\begin{array}{l}\text { cooperation with } \\
\text { hospitals nearby }\end{array}$ & $1500-2500$ \\
\hline
\end{tabular}

\subsection{Methods}

\subsubsection{Data Collection}

Based on literature review, expert consultation and pre-interview, we finally determined the semi-structured interview outline: "Service Status of Private Pension Agencies Integrated Medical and Nursing".

The main contents of the interview outline are listed as follows: 1) General situation, occupancy, allocation of facilities and equipment, and staffing of pension agency; 2) What are medical-nursing integrated services provided by pension agency? Does it meet the needs of the elderly? Are there any difficulties in the provision of service? State the causes of these difficulties. 3) How are the pension agencies currently operating? Are there any difficulties in operating? State the causes of these difficulties. 4) What are the main difficulties in the current development of pension agency? What policy support do you want?

The interview team consisted of 1 master's tutor and 3 master's students, and the team members were trained in advance on the content of the interview outline. Each interviewee was asked by the same researcher, and other researchers supplemented questions and assisted in recording. The interviewers informed the interviewees of the purpose and process of this study, promised the confidentiality of the interview in advance, then conducts face-to-face in-depth interviews after obtaining informed consent. The interview time for each person is 30 - 60 minutes, and the interview contents are well recorded and saved by recording.

\subsubsection{Data Analysis}

After each interview, we transcribed the interview recordings into text materials in time, and used the Colaizzi 7-step analysis method to analyze the interview data [9]. We carefully read all the interview materials, sorted out the recurring ideas in the interview, coded and classified these ideas, refined the theme based on the main ideas of the interviewees, and finally returned the interview mate- 
rials to the interviewee for verification.

\section{Results}

\subsection{Lack of Medical Service Standards, and Poor Integration of Medical and Nursing}

First of all, A and B (representing pension agencies that have internal hospitals) can provide outpatient services and inpatient services, and can be paid by medical insurance. The service items include diagnosis and treatment, physical examination, health consultation, health rehabilitation, and traditional Chinese medicine. However, the interview found that for the elderly who did not take the initiative to obtain medical services, they (A and $B$ ) only provided basic living care, but did not provide health management and health promotion services. In addition, they also have restrictions on medical insurance reimbursements for the elderly. Most of the elderly have got medical insurance of special disease (such as hypertension, diabetes, uremia, etc.), and patients with such diseases need long-term continuous medication and imposed weightily economy burden on their family. Medical insurance of special disease can only be reimbursed in a tertiary hospital, or a secondary hospital plus a first-level hospital, while the internal hospital is usually a first-level hospital, which can neither work alone to meet the medical needs of the elderly with special diseases, nor cooperate with tertiary hospital to provide convenience of prescribing drugs for the elderly. Therefore, the elderly with special disease have to go outside to a tertiary hospital for prescribing drugs.

Secondly, C and D (representing pension agencies that have internal clinic) provide following services, including minor illness diagnosis, health consultation, and assistance in medication. Meanwhile, C and D also cooperates with nearby private hospitals. Once the elderly are sick, they will be sent to hospital for treatment in time through a green channel. However, this study found that the internal clinic can neither be paid through medical insurance, nor can it meet the basic medical service needs of the elderly in the equipment, so the integration of medical and nursing is a empty shell. Internal clinic in pension agencies has not been included in the scope of medical insurance payment nowadays, so medical services provided by internal clinic are out-of-pocket payment items.

In the end, $\mathrm{E}$ and $\mathrm{F}$ (representing pension agencies that cooperate with hospitals nearby) do not have independent medical institutions, but the cooperative hospitals provide services such as pick-up, drop-off, and appointment registration for elderly residents. In addition to the above services, hospitals and pension agencies operate independently.

\subsection{Insufficient Number and Low Quality of Medical-Nursing Integrated Service Team}

According to the national standard for the ratio of caregivers-to-elderly, the ratio of caregivers to self-care elderly should not be less than 1:15, and the ratio of 
caregivers to device-aided elderly should not be less than 1:3. However, the survey found that none of the six pension agencies reached the national standard of caregiver-to-elderly ratio, and some of them even had a far lower ratio of caregivers-to-elderly, in which the ratio of caregivers to self-care elderly was 1:30 and the ratio of caregivers to device-aided elderly was 1:6. Most caregivers were domestic helpers previously, and worked as caregivers with only simple training within the agencies, who are women aged 40 and over with a high school degree or below from nearby rural areas. That is, they lack relevant training and assessment procedures, so they lack professional nursing skills and experience, and have a low level of care.

In addition, $\mathrm{A}$ and $\mathrm{B}$ also have the problem of insufficient medical staff and lack of training except the above problems. Both A and B indicated that the number of medical staff, aged around 30, cannot meet aging people's demand and most of they have college or undergraduate education, which means that pension agencies lack highly educated professionals and experienced medical staff. Furthermore, such factors as poor career prospects, job nature have led to high mobility of medical staff, making it difficult for agencies to train and assess them.

\subsection{Lack of Policy Support for Medical-Nursing Integrated Services and Single Fund-Raising Channel for Pension Agencies}

According to the interview, government has little policy support for private pension agencies. In terms of financial support, government only provides operating subsidies based on the number of elderly residents in pension agencies, and there are regional differences in the amount of subsidies in the main urban area of Chongqing. For pension agencies in District A, there are restrictions on receiving subsidies, which requires that the elderly from District A must live in pension agencies in District $\mathrm{A}$, and there are three levels on the amount of subsidies according to the size of pension agency (100 yuan/month, 60 yuan/month, and 30 yuan/month), which is too low to solve the problem of institutional funding. The government's financial support for integration of medical and nursing is not enough, so fund-raising channels of these six pension agencies are mainly self-raised funds and service charges for the elderly. At present, these agencies all have varying degrees of operational difficulties, four of which (A, B, $\mathrm{C}, \mathrm{D})$ are facing greater operational pressure than the other due to the increase in manpower and facilities costs from the internal medical institutions.

\subsection{A Heavy Financial Burden of High Service Fee for the Elderly}

The interview shows the minimum charge for A is 3500 yuan/month, for B is 3000 yuan/month, for $\mathrm{C}$ and $\mathrm{D}$ is 1600 yuan/month, and for $\mathrm{E}$ and $\mathrm{F}$ is $1500 \mathrm{yu}-$ an/month, which is mainly for self-care elderly. The service charge increase for device-aided elderly and vary with room configuration, service content and nursing level. For example, the service fee for device-aided elderly is up to 10,000 
yuan per month in A, including services of personal hygiene, meal delivery and laundry, etc provided by the caregiver, while the service fee for self-care elderly is 4900 yuan per month in A, including service of meal delivery and laundry, of which accommodation costs 4600 yuan and meal delivery costs 300 yuan. The agency $\mathrm{E}$ has divided the elderly care into three levels, of which the fee for first-degree nursing, the target group of which is the elderly with serious ill in bed, is up to 4000 yuan per month. Furthermore, nursing fees in pension agency cannot be reimbursed by medical insurance, so the elderly can only pay all nursing fees at their own expense. The financial ability of the elderly is limited, coupled with expenses like disease treatment, medicine, and daily life, they usually need financial assistance from their children.

\section{Conclusion}

\subsection{Clarifying the Goals of Medical Services to Achieve the Integration of Medical and Nursing}

In terms of internal hospital model (like A and B), the internal hospitals should change their service goals, which should provide medical services like health education (health regimen and health consultation), health management (establishing health records and formulating health tracking plans), long-term rehabilitation nursing, psychological counseling, and disease diagnosis [10]. Then they should introduce the medical equipment and medical staff needed in line with the medical service. What's more, A and B need to cooperate with local tertiary hospitals with special disease designated qualifications so as to ensure that the elderly with special diseases can receive timely treatment, and they should regularly assist the elderly with special diseases to go to tertiary hospitals for physical examination and get medicines to meet the needs of the elderly.

As far as internal clinic model (like $\mathrm{C}$ and $\mathrm{D}$ ), the internal clinics should bear the responsibility of handling medical emergencies and doing a good job in health management. The main responsibilities of the clinic are as follows: the clinics should immediately transfer the elderly to a hospital after the first emergency treatment once the elderly suffer from sudden illness or injury; they shall establish aging people's health files, and make regular follow-up interventions to master the health status of the elderly; they should carry out health education to improve the health awareness of the elderly so that the elderly do not get sick or less sick.

As for cooperation with nearby hospitals model (like E and F), pension agencies and hospitals need to further deepen their cooperation. Cooperative hospitals should regularly go to pension agencies to provide outpatient medical services and establish health files for the elderly, which is conducive to disease examinations and emergency treatment of the elderly later, and they shall feed back the basic physical information of the elderly to pension agencies for carrying out targeted care. While pension agencies need to send caregivers to cooperative hospitals to participate in training for nursing the elderly with chronic diseases 
or disabilities in order to improve nursing knowledge and skills.

\subsection{Strengthening the Construction of Medical-Nursing Integrated Service Team}

Caregivers, as the main force of service in pension agencies, are responsible for the daily care and basic nursing of the elderly, and hence their low professional skill has a significant impact on the quality of pension service and brings danger to the elderly [11]. At present, caregivers are short of professional skills and lack nursing-related knowledge. Therefore, it is necessary to encourage nursing professionals to engage in pension services through salary, welfare and career development, so as to solve the problem of insufficient nursing professionals and provide a guarantee for agencies to introduce nursing professionals. In addition, pension agencies should pay attention to the training of caregivers to improve their professional skills. On one hand, the pre-job training of caregivers should be enhanced: the government should actively organize the vocational qualification and skill level certification of caregivers, and establish a caregiver certification system and standards of skills and operating [12]. On the other hand, the on-the-job training for caregivers should be strengthened: the work ability of caregivers can be improved through regular training for them on the nursing knowledge and skills for the elderly.

Public hospitals have dominated China's health system for a long time and attracted excellent human resources. Therefore, considering such factors as career prospect, there are very few high-level doctors who want to work in hospitals of pension agencies for a long time [13]. Regarding insufficient medical staff, government should cultivate and expand the team of medical staff. That is, through adding geriatrics professional courses in medical schools, the training of geriatric medical professionals is strengthened and the society pays more attention to geriatric care, so as to alleviate the shortage of geriatric medical staff in the aging society [14]. Meanwhile, government should establish and improve technical title assessment system for medical staff in pension agencies, and form a salary management system to attract more medical staff to participate in China's pension services [10]. As for a lack of training among medical personnel, pension agencies shall focus on the training of on-the-job medical staff. Firstly, pension agencies shall conduct unified management in strict accordance with requirements of the health department, including the establishment of a rotation training system and the promotion of vocational evaluation on medical-nursing integrated skills [15]. Secondly, pension agencies should regularly dispatch medical staff to professional medical institutions for practical training or invite geriatric experts to conduct lectures, and then assess the effects of learning to enhance their professional capabilities.

\subsection{Increasing Policy Support of Government and Investment of Social Organization}

Pension service industry is a high-risk industry for its large investment, long re- 
turn periods, and fierce market competition. If pension agencies provide medical-nursing integrated services, the requirements for equipment and manpower are much higher than ordinary ones, so the cost will be higher [16]. Aging of Chinese population is becoming more and more severe, and pension and medical are facing huge challenges nowadays. Although the medical-nursing integrated pension agencies can solve the problems of medical and pension at the same time, the current development is not ideal. Therefore, the government needs to introduce relevant preferential policies to support its development and actively respond to the population aging [17]. The government should actively support pension agencies to provide medical-nursing integrated services, make full use of resources to increase support for integration of medical and nursing, including providing preferential policies in terms of land, taxation, water, electricity and heat, and increase the amount of construction subsidies and operating subsidies, that is, provide support in the form of medical-nursing integrated subsides, added beds subsides, nursing subsides and awards for grade evaluation, so as to reduce the operating pressure of pension agencies [18]. In addition, the government should strongly encourage non-profit organizations, social groups, and individuals to participate in medical-nursing integrated services, and set up money-raising projects for medical-nursing integrated services to alleviate the operational difficulties of pension agencies.

\subsection{Accelerating the Popularization of the Long-Term Care Insurance System to Provide Protection for the Elderly in Pension Agencies of Medical-Nursing Integration}

China's high fees for medical-nursing integrated services put greater economic pressure on the elderly with low income at the moment, which not only limits aging people's demand for pension, but also hinders the development of the medical-nursing integrated industry. Long-term care insurance system incorporates the medical and nursing of the elderly into the social security system and solves the medical care of aging people with disabilities in the form of insurance, the mechanism of which is that citizens start to pay insurance premiums at a certain age, and they can enjoy the economic subsidies for medical care provided by insurance system through identification when they are old [19]. Long-term care insurance is the best way to solve the problem of China's rapid population aging, large amount, senility, the lack of national pensions. However, a comprehensive long-term care insurance system has not yet been formed in China due to insufficient time and experience. Therefore, China can learn from the valuable experience of developed countries such as Japan and Germany to popularize the long-term care insurance system suitable for China by the following measures: clarify the responsibilities of each subject through legislation, build a diversified financing mechanism, establish a standardized disability rating system, and strengthen the training of nursing professionals [20], which not only closely link pension and medical to form a more mature social welfare system that combines medical and pension, but also reduce the economic burden of the elderly and 
promote the healthy development of pension service industry.

Due to the limitations of human, financial and material resources, this study only conducted a cross-sectional survey on medical-nursing integrated services in 6 pension agencies in Chongqing A District, and scope of the survey was not extensive enough.

\section{Conflicts of Interest}

The authors declare no conflicts of interest regarding the publication of this paper.

\section{References}

[1] National Bureau of Statistics (2020) Statistical Communique of the People's Republic of China on the 2019 National Economic and Social Development. http://www.stats.gov.cn/tjsj/zxfb/202002/t20200228 1728913.html

[2] Liu, B. (2019) "Integration of Medical and Nursing" Becomes the Old Age Security. People's Tribune, 100-101.

[3] Gao, H. (2017) Research on the Fund Security of City Pension Agency with "Medical \& Nursing Combined" Mode. MD, Jilin University, Changchun. https://kns.cnki.net/KCMS/detail/detail.aspx?dbname=CMFD201702\&filename $=10$ 17158943.nh

[4] Sun, J.J. and Tian, J.Y. (2020) An Analysis of Integrated Health Care and Social Services Policies of China in the Perspective of New Health Aging. China Sport Science and Technology, 56, 58-65.

[5] Si, J.P., Guo, Q., Wang, X.J., et al. (2020) A Study on the Policy Text of Integrated Health Care and Social Services for Seniors in China from the Perspective of Policy Tools. Chinese Journal of Health Policy, 13, 49-55.

[6] Shen, J.L., Shen, Y. and Wang, H.J. (2019) Research on the Model of "Integration of Medical Care and Nutrition" in the Perspective of Healthy Aging. Price: Theory \& Practice, 15-19.

[7] Wu, L.Q., Lu, W.J. and Yao, K.Q. (2019) Analysis on the Factors Influencing the Choose of Medical-Nursing Combined Services among the Elderly People in Urban China. Chinese General Practice, 22, 10-13.

[8] Chongqing Municipal People's Government (2017) Notice of the General Office of the Chongqing Municipal People's Government on Printing and Distributing the "Thirteenth Five-Year Plan" for the Development of the Elderly Career and the Construction of the Elderly Care System. http://www.cq.gov.cn/zwgk/fdzdgknr/lzyj/xzgfxwj/szfbgt 38656/202001/t20200115 4753846.html

[9] Liu, M. (2019) Using an Example to Illustrate Colaizzi's Phenomenological Data Analysis Method. Journal of Nursing Science, 34, 90-92.

[10] Huang, J.Y. and Nie, Q.Q. (2017) Research and Countermeasures on the Integration of Medical and Nursing-Taking 6 Private Pension Agencies in Jiangsu as an Example. Health Economics Research, 21-23.

[11] Wang, B.Y., Xu, M.J. and Wu, Q.J. (2018) Status Quo and Countermeasures for Developing Institutions Combining Old-Age Care and Medical Care in Guangxi. Chinese General Practice, 21, 3741-3745.

[12] Wang, H.T. (2019) Take a Holistic Approach to Promote the Development of 
Pension Services Integrating Elderly Care and Medical Services. Macroeconomic Management, 34-38.

[13] Liu, S.Y., Liu, M., Gui, Y., et al. (2016) Development of Old-Age Care Institutions of Medical-Nursing Combined in Beijing: Problems and Solutions. Chinese General Practice, 19, 4034-4038.

[14] Zhou, X.L., Jiao, Y.H. and Wang, C. (2019) Problems and Countermeasures in the Medical-Nursing Integrated Service System of Xi'an Elderly Care Institutions. Chinese Journal of Gerontology, 39, 1210-1213.

[15] Zhang, Y.J. (2019) The Old-Age Service System with Integration of Medical and Nursing Needs to Be Constructed Urgently. People's Tribune, 102-103.

[16] Zhang, X.J. (2018) Research on the Current Situation, Problems and Countermeasures of Medical Care and Pension Service in Changchun City. MD, Jilin Agricultural University, Changchun.

https://kns.cnki.net/KCMS/detail/detail.aspx?dbname=CMFD201901\&filename $=10$ 19811726.nh

[17] Shi, C. (2019) Qualitative Research on the Development Status and Dilemma of the Medical-Aged Care Combined Institutions in Taiyuan City. MD, Shanxi Medical University, Taiyuan.

https://kns.cnki.net/KCMS/detail/detail.aspx?dbname=CMFD201902\&filename $=10$ 19611769.nh

[18] Jin, Q. (2017) Analysis of the Status Quo and Countermeasures of Urban Elderly Care Institutions with Integration of Medical and Nursing-Taking C Elderly Care Institutions in Shangrao City, Jiangxi Province as an Example. MD, Jiangxi University of Finance and Economics, Nanchang.

[19] Dang, R.Y., Zhou, Y., Xu, L., et al. (2017) Research on the Modes and Countermeasures of Urban Aged Care Institutions with the Combination of Medical and Nursing. Practical Preventive Medicine, 24, 580-582.

[20] Li, Y.H. and Jiang, L. (2020) Reform and Enlightenment of Japan's Long-Term Care Insurance System. Reform of Economic System, 167-172. 